\section{Steroid estrogens in primary and tertiary wastewater treatment plants}

\section{Olga Braga', George A. Smythe', Andrea I. Schäfer ${ }^{2}$ and Andrew J. Feitz}

1 Ray Williams Biomedical Mass Spectrometry Facility, Faculty of Medicine, University of New South Wales, Sydney NSW 2052 Australia

${ }^{2}$ Civil, Mining and Environmental Engineering, University of Wollongong, Wollongong NSW 2522, Australia Centre for Water and Waste Technology, School of Civil and Environmental Engineering, University of New South Wales,

Abstract: The concentrations of two natural estrogens (Estrone (E1) and Estradiol (E2)) and one synthetic progestin (Ethinylestradiol (EE2)) were measured for different unit operations in an advanced sewage treatment plant and in a large coastal enhanced primary sewage treatment plant. The average influent concentration to both plants was similar -55 and 53 $\mathrm{ng} / \mathrm{L}$ for $\mathrm{E} 1$ and 22 and $12 \mathrm{ng} / \mathrm{L}$ for $\mathrm{E} 2$ for the advanced and enhanced primary STPs, respectively. The activated sludge process at the advanced STP removed up to $85 \%$ and $96 \%$ of $E 1$ and E2, respectively. The enhanced primary sewage reatment process. EE2 was not been detected during the study period in the influent or effluent of either STP. The difference in the observed removal between the two plants is primarily linked to plant performance but the extent to which removal of steroid estrogens is due to bacterial metabolism (i.e. the advanced STP) rather than adsorption to the bacterial biomass remains unclear. The poor removal observed for the coastal enhanced primary STP may have implications for the receiving environment in terms of a greater potential for abnormal repo

Keywords: Estrone, estradiol, ethinylestradiol, estrogen, wastewater, sewage.

\section{Introduction}

The release of steroid estrogens into the environment has been linked to abnormal reproductive systems in freshwater and marine dwelling animals (Purdom et al., 1994; Desbrow et al., 1998; Routledge et al., 1998). Human excretion is considered the principal source of estrogens and progestins in the environment, predominantly via discharge from sewage treatment plants (Sumper, 1998; Sole et al., 2000; Ariese et al., 2001). While there is increasing data on the concentration or estrogens in rivers (Kuch and Ballschmilter, 2001, Shyder et al., 2001, Alder et al., 2001) and wastewater effluent (Terne et al., 1999; Baronti et al., 2000; Huang and Sedlak, 2001), there are comparatively few studies that have determined the concentration of estrogens in the raw sewage (prior to sample pre-treatment with filtration) due to the difficultie encountered when processing a high organic matter, fats and suspended solids matrix. This paper reports on measurement

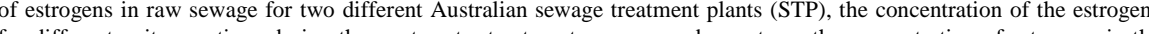

\section{Materials and Methods}

\section{Sampling Sites}

A small inland advanced sewage treatment plant and large coastal enhanced primary sewage treatment plant were studied in order to assess steroid estrogen removal rates for different unit operations. The advanced sewage treatment plant is locate in western Sydney and services only domestic sewage. This plant consisted of activated sludge treatment ( 2 sequential batc bioreactors). The secondary effluent taken to the tertiary treatment unit that consisted of continuous microfiltration (CMF), reverse osmosis (RO) and chlorination/de-chlorination. The activated sludge treatment consists of two basins with anoxic and aerobic zones. The solids retention time (SRT) is approximately 16 days and the hydraulic retention time (HRT) is hours ( 2 hours each in the anoxic zone and aerobic zones). The coastal enhanced primary sewage treatment plant is located

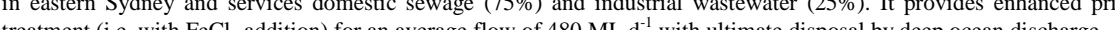

\section{Standard and SPE Preparation}

Estrone $\left(\mathrm{E}_{1}\right)$, estradiol $\left(\mathrm{E}_{2}\right)$, ethinylestradiol $\left(\mathrm{EE}_{2}\right)$, and deuterated estrone-2, 4,16,16-d4 $\left(\mathrm{d} 4-\mathrm{E}_{1}\right)$ were obtained from Sigma Aldrich (Sydney, Australia). The d4- $\mathrm{E}_{1}$ was used as the inlernal standard. Stock solutions of individual non-deuterated standards and deuterated internal standard were prepared by dissolving known amounts of in methanol to obtain a concentration of $0.10 \mathrm{mg} \cdot \mathrm{mL}$. Working standard solutions were obtained by further diluting stock solutions with water to obtain final concentrations of $0.5 \mathrm{pg} . \square \mathrm{L}^{-1}$ to $500 \mathrm{pg} . \square \mathrm{L}^{-1}$. The stock solution of internal standard was further diluted with water to obtain a final concentration of $100 \mathrm{pg} . \square \mathrm{L}^{-1}$. HPLC grade methanol and acetonitrile were obtained from Ajax Finechem (Sydney, Australia). Other solvents were of analytical grade and they were used as supplied. Milli-Q water was used for all experimental procedures. Analytes were extracted from aqueous samples by solid phase extraction (SPE) using Visiprep DL Vacum Manifold (Supeco, Sydney, Autralia), the SPE was sequentilly conditioned with $2 \times 10$ mL

\section{Sample Collection}

Duplicate samples were collected in 1L Pyrex glass bottles from each sampling point within the two STPs. In the Advanced STP, samples were collected from the raw sewage, outlet from sequential batch reactor (SBR), inlet/outlet from cross flow microfiltration (CMF), outlet from reverse osmosis (RO) and after dechlorination. For the Enhanced Primary STP, samples were collected from the raw sewnge and trated efluent. All samples were passed hogh SE, dided and stored in a 10-mL the tube on the collection)
of cold

\section{Sample Preparation and Solid Phase Extraction}

Analytes were extracted from $0.5 \mathrm{~L}$ (raw sewage) to $1 \mathrm{~L}$ for all other samples. Before samples were processed, internal standard (see above) was ad $0.5 \mathrm{~L}$ to an AP-15 filter (Millipore, Sydney, Australia). This step was performed to avoid SPE cartridge plugging. Sample loading was achieved by passing standards and environmental water samples through the LC-18 SPE cartridge. After sample loading, cartridges were dried in a vacuum desiccator for 30 to $40 \mathrm{~min}$. Elution of the analytes was achieved by passing $2 \times 5$ $\mathrm{mL}$ methanol that was collected in a $10 \mathrm{~mL}$ culture tube with screw cap. The collected solution was dried down under vacuum and reconstituted to $1 \mathrm{~mL}$ with acetone before derivatisation and analysis.

\section{Sample Derivatization for GC-MS Analysis}

The derivatization was carried out using a modified version of the method used by Nakamura et al. (2001) for the pentafluorobenzyl-trimethylsilyl derivative. To the acetone extract, $100 \mu \mathrm{L}$ of $10 \%$ aqueous potassium carbonate and $10 \mu \mathrm{L}$ of pentafluorobenzylbromide reagent were added, and were kept at $70^{\circ} \mathrm{C}$ for 1 hour. After cooling, the solvent was reduced to $100 \mu \mathrm{L}$ under vacuum. $1 \mathrm{~mL}$ of toluene was added, and the organic phase was washed with $0.5 \mathrm{~mL}$ of Milli-Q water. The water layer was discarded and the toluene layer completely removed under vacuum. $100 \mu \mathrm{L}$ of trimethylsililacetamide was then added to the vial and kept at room temperature for $30 \mathrm{~min}$. Toluene was added to $1 \mathrm{~mL}$ before analyses.

\section{Gas Chromatography Mass Spectrometry Conditions}

All GC-MS analyses were carried out using an Agilent 5890 gas chromatograph interfaced to an Agilent 5989B MS Engine (Agilent Technologies, Ryde, Australia). Chromatographic separations were performed with an HP-5MS capillary column $\left(30 \mathrm{~m} \times 0.25 \mathrm{~mm}\right.$ i.d. $\times 0.25 \square \mathrm{m}$ film thickness). The $\mathrm{GC}$ oven temperature was programmed at $150^{\circ} \mathrm{C}$ for $1.5 \mathrm{~min}$ and the $36 \mathrm{C}$ per minute to $310 \mathrm{C}$, final hold $7.0 \mathrm{~min}$. The GC-MS interface heater, he ion source, quadrupole, and injection por pressure of $241 \mathrm{kPa}(1.1 \mathrm{~min})$ and purge time delay of 8 min. The MS analyses were performed with an ecetron-captre negative-ion (ECNI) source, using methane as reagent gas (Ultrapure grade, Matheson Gas Products Inc) and selected io monitoring mode. The $\left[\mathrm{M}^{-}\right]$ion and [M-TMS $]$ions were monitored for all compounds with a dwell time of $100 \mathrm{~ms}$ pe monitoring mode. The $[\mathrm{M}]$ ion and $[\mathrm{M}-\mathrm{TMS}$. ions were monitored for all compounds with a dwell time of $100 \mathrm{~ms}$ per
single ion The injection volume was $1.0 \square \mathrm{L}$. The instrumental limit of detection (LOD) for E2 and EE2 was $0.1 \mathrm{pg} . \square \mathrm{L}^{-1}$ of injection and for $\mathrm{E} 1$ was $0.5 \mathrm{pg} . \square \mathrm{L}^{-1}$ injection, which was estimated at a signal-to-noise ratio of 3 . The method limit of quantification (LOQ) was determined to be $1 \mathrm{ng} . \mathrm{L}^{-1}$ for raw sewage and $0.1 \mathrm{ng} . \mathrm{L}^{-1}$ for secondary and tertiary effluents. Note that this is the LOQ of the raw sample prior to any pre-treatment (e.g. filtering). 


\section{Results}

The average concentrations of E1, E2 and EE2 in the raw sewage of the advanced STP were 55, 22 and $<1 \mathrm{ng} / \mathrm{L}$ respectively. The average concentrations of E1, E2 and EE2 in the raw sewage of the enhanced primary STP were 53, 12 and $<1 \mathrm{ng} / \mathrm{L}$ respectively. The E1 and E2 figures are generally in good agreement with reported raw sewage concentration in other studies but the EE2 figures were consistently lower (Table 1). The fact that there is little difference between the prefiltered results obtained in this study and filtered samples from other studies suggests that estrogens are mostly present in the colloidal or dissolved fraction in the raw sewage. The extent of estrogen removal for each unit process in the advanced sewage treatment plant is summarised in Figure 1. The sequential batch reactor (SBR) removes on average $85 \%$ of the incoming E1 and 96\% of the E2. These figures do not consider the potential transformation of E2 to E1 (Ternes et al. 1999b; Lee and Lia, 2002). The biologically treated effluent is then stored in a holding tank before passing through the 12 . 0.1 nel,

Table 1. Reported individual estrogen concentrations in the influent to sewage treatment plants and an indication of which analytical methods pre-filter before total estrogen analysis of water samples

\begin{tabular}{|c|c|c|c|l|}
\hline $\begin{array}{c}\mathrm{E} 1 \\
(\mathrm{ng} / \mathrm{L})\end{array}$ & $\begin{array}{c}\mathrm{E} 2 \\
(\mathrm{ng} / \mathrm{L})\end{array}$ & $\begin{array}{c}\mathrm{EE} 2 \\
(\mathrm{ng} / \mathrm{L})\end{array}$ & Pre-filter & Reference \\
\hline $4-47$ & $13-70$ & $2-28$ & $\mathrm{Y}^{*}$ & Lagana et al. (2000) \\
\hline $9-48$ & $18-140$ & $<0.2-8.8$ & $\mathrm{Y}$ & Johnson et al (2000) \\
\hline $27-40$ & $15-21$ & -.8 & $\mathrm{Y}$ & Ternes et al (1999a) \\
\hline $7.6-8.6$ & $4.9-7.2$ & $2.0-5.2$ & $\mathrm{Y}$ & Mouatassil-Souali et al. (2003) \\
\hline $4-25$ & $25-132$ & $0.40-13$ & $\mathrm{Y}$ & Baronti et al. (2000) \\
\hline$<1-25$ & 11 & - & $\mathrm{Y}$ & DAscenzo et all. (2003) \\
\hline- & $20-94$ & - & $?$ & Nasu et all. (2001) \\
\hline 39 & 19 & $<5$ & $?$ & Chapman (2003) \\
\hline $54.9-76.6$ & $12.2-19.5$ & $6.2-10.1$ & $\mathrm{Y}$ & Anderson et al. (2003) \\
\hline $36-81$ & $6.3-29$ & $<1$ & $\mathrm{~N}$ & This study (Enhanced Primary STP) \\
\hline $29-93$ & $2.2-72$ & $<1$ & $\mathrm{~N}$ & This study (Advanced STP) \\
\hline
\end{tabular}

$*$ sample residual on filter paper washed with methanol

Unlike the advanced STP where some $85-96 \%$ of estrogens are removed in the initial biological treatment stage, there i effectively no removal of the estrogens during treatment at the enhanced primary STP as the solids concentration and 政 equating to only $14 \%$ removal for E1 and $5 \%$ for E2 (Figure 2).

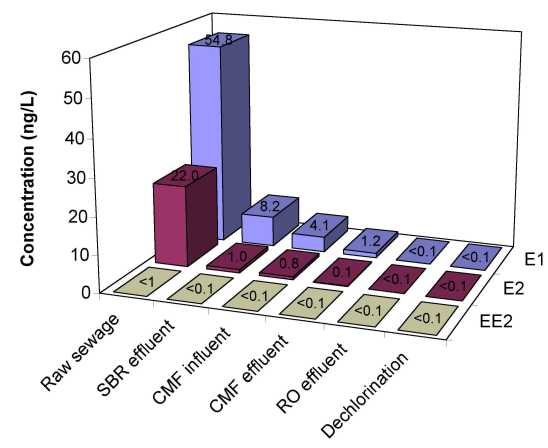

Figure 1. Average estrogen removal at the advanced STP for different unit operations from 16 samples (Estrone $\left(E_{1}\right)$, estradiol $\left(E_{2}\right)$ and ethinylestradiol $\left(E_{2} E_{2}\right)$. $S B R=$ sequential batch reactor; $C M F=$ cross-flow microfiltration: $R O=$ revers osmosis.

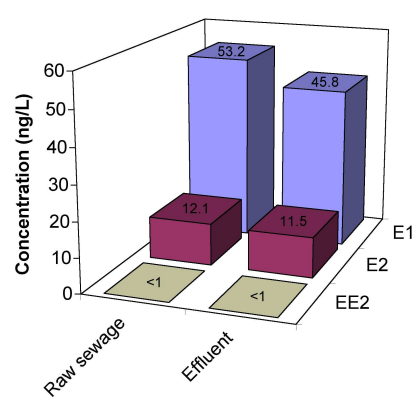

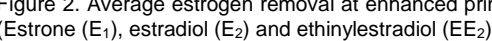

\section{Discussion}

The percentage removal for estrogens obtained during biological treatment at the advanced sewage treatment plants is consistent with other studies, which typically range from $60-85 \%$ (Ternes et al., 1999b; Baronti et al., 2000; Johnson $e$ 1. 2000). The SBR is therefore generally effective for the resol (The of adsorption onto bacterial biomass or biological degradation remains unclear. Further studies are required to accurately determine the degree of partitioning during treatment together with the removal mechanism within biological treatment. Several studies have performed mass balances around the biological treatment stage at STPs and shown that most of the estrogens removal can be accounted for by biological oxidation (Holbrook et al., 2002; Anderson et al., 2003). Radiolabelled estrogen studies have confirmed that E2 is susceptible to mineralization but EE2 is resistant to mineralization (Layton et al., 2000). Other authors have also confirmed that E1 and E2 are readily degraded by sewage bacteria during small batch experiments (Ternes et al., 1999b; Lee and Liu, 2002).

Poor removal of estrogens is observed at the enhanced primary STP in contrast to the advanced STP. This result is consistent with the reported performance of primary clarifiers in secondary or tertiary treatment plants (Holbrook et al., 2002; Anderson et al., 2003). With only $14 \%$ of $\mathrm{El}$ and $5 \%$ of $\mathrm{E} 2$ being removed at the plant, it is important to consider the potential impacts of such a large load of estrogens on the receiving environment. The high levels of dilution obtained during ocean disposal may prove suficient for the prevention of endocine effects in marine animals but could prove problematic for discharges into large bays or harbours where flushing is limited (Atkinson et al., 2003). The life-time for estrogens in fully aerobic seawater is in he order of weeks (Ying and Kookana, 2003). Enhanced primary STPs are considered to be on Los Angles, Hon Kong Sao Paulo, Rio de Janeiro and Jstanul (Harleman and Murcott, 1999; Erogle et al, 2001). This Pe load of estrogens to the receiving environment.

\section{Conclusions}

The concentrations of estrone $\left(\mathrm{E}_{1}\right)$, estradiol $\left(\mathrm{E}_{2}\right)$ and ethinylestradiol $\left(\mathrm{EE}_{2}\right)$ in Australian sewage is similar to that reported for other countries. High removal efficiencies are observed during biological treatment but poor removal is observed for potential for ary treatment plants. This poor removal has implications for the receiving environment in terms of a greater where flushing is limited. 


\section{Acknowledgements}

Scholarship and financial support from BMSF and the UNSW Faculty of Engineering for Olga Braga is gratefully (Sydney Water Corporation). Comments provided by David L. Sedlak are also greatly appreciated. Matthias Bonerz and Thomas Ternes (ESWE Wiesbaden) are acknowledged for their support with initial studies funded by BMB\&F, Germany, and the authors would also like to thank Mr Ray Williams for the generous provision of mass spectrometer equipment.

\section{References}

Alder, P., Steger-Hartmann, T., and Kalbfus, W. (2001) Distribution of natural and synthetic estrogenic steroid hormones in water

Andersen, H., Siegrist, H., Halling-Sørensen, B. and Ternes, T.A. (2003) Fate of estrogens in municipal sewage treatment plant. Eviro Sci. Technol. 37, 4021-4026.
Atkinson, S., Atkinson, M.J. and Tarrant, A.M. (2003) Estrogens from sewage in coastal marine environments. Environ. Health Perspect. Baronti, C. Curini, R., D'Ascenzo, G., Di Corcia, A. Gentili, A and Samperi, R. (2000) Monitoring natural and synthetic estrogens a

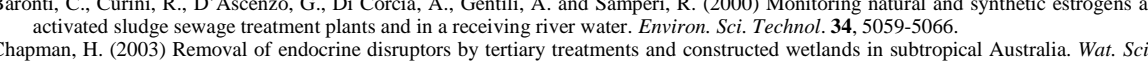
Technol. 47(9), 151-156.

D'Ascenzo, G., Di Corcia, A., Gentili, A., Mancini, R., Mastropasqua, R., Nazzari, M. and Samperi, R. (2003) Fate of natural estrogen Desbrow, C., Routledge, E.J., Brighty, G.C., Sumpter, J.P. and Waldock, M. (1998) Identification of estrogenic chemicals in STW effluent. 1.Chemical fractionation and in vitro biological screening. Environ. Sci. Technol. 32, 1549-1557.
Eroglu, V., Sarlkaya, H.Z. and Aydin, E. (2001) Planning of wastewater treatment and disposal systems of Istanbul metropolitan area.
Water SCi. Technol $\mathbf{4 4}, 31-38$. Harleman, D.R.F. and Murcott, S. (1999) The role of physical-chemical wastewater treatment in the mega-cities of the developing world. Water Sci. Technol. 40, $75-80$

Holbrook, R.D., Novak, J.T., Grizzard, T.J. and Love, N.G. (2002) Estrogens receptor agonist fate during wastewater and biosolids treatment processes: A mass balance analysis. Environ. Sci. Technol. 36, 4533-4539.
Huang, C.H. and Sedlak, D. (2001) Analysis of estrogens in municipal waste water effluent and surface water using enzyme-linked immunosorvent assay and gas chromatography/tandem mass spectrometry. Environ. Toxicol. Chem. 20, 133-139. Johnson, A.C., B. Belfroid, and A. Di Corcia (2000) Estimation of steroid estrogens inputs into activated sludge treatment works an observations on their removal from the effluent. Sci. Total Environ. 256, 163-173.

Johnson, A.C. and Sumpter, J.P. (2001) Removal of endocrine-disrupting chemicals in activated sludge treatment works. Environ. Sci Kuch, H.M. and Ballschmitter, K. (2001) Determination of endocrine-disrupting phenolic compounds and estrogens in surface an

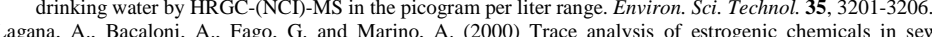
Lai, K.M., Johnson, K.L.. Scrimshaw, M.D. and Lester, J.N. (2000) Binding of waterborne steroid estrogens to solid phases in river and

estuarine systems. Environ. Sci. Technol. 34, 3890- 3894.
Layton, A.C., Gregory, B.W., Seward, J.R., Schultz, T.W. and Sayler, G.S. (2000) Mineralization of steroidal hormones by biosolids in Lee, H.B. and Liu, D. (2002) Degradation of 17ß-estradiol and its metabolites by sewage bacteria. Wat. Air Soil Poll. 134, 353-368. Mouatassim-Souali, A., et al., (2003) Validation of a quantitative assay using GC/MS for trace determination of free and conjugated

estrogens in environmental water samples. J. Sep. Sci. 26, 105-111.
Nakamura, S., Sian, T.H. and Daishima, S. (201) Determination of estrogens in river water by gas chromatography-negative-ion Purdom, C.E., Hardiman, P.A., Bye, V.J., Eno, N.C., Tyler, C. and Sumpter, J.P. (1994) Estrogenic effects of effluents from sewage treatment works. Chem. Ecol. 6, 275-285.
Routledge, E.J., Sheahan, D., Desbrow, C., Brighty, G.C., Waldock, M. and Sumpter, J.P. (1998) Environ. Health Perspect. 32, 1559-

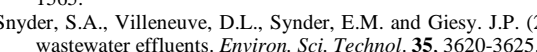
Ternes, T.A.; Stumpf, M.; Mueller, J.; Haberer, K.; Wilken, R.-D.; Sevos, M. (1999a) Behaviour and occurrence of estrogens in

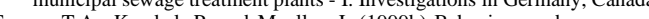

treatment plants - II.

Aerobic batch experiments with activated sludge. Sci. Total Environ. 225, $91-99$.
Ying, G.G. and Kookana, R.S. (2003) Degradation of five Selected Endocrine Dissupting Chemicals in Seawater and marine Sediments.
Environ. Sci. Technol. 37, 1256-1260. 